Reprinted from Coker, J. K., \& Borders, L. D. (2001). An analysis of environmental and social factors impacting adolescent problem drinking. Journal of Counseling and Development, 79(2) , 200-208. The American Counseling Association. Reprinted with permission.

No further reproduction authorized without written permission from the American Counseling Association: http://www.counseling.org/

\title{
An Analysis of Environmental and Social Factors Affecting Adolescent Problem Drinking
}

\author{
J. Kelly Coker and L. DiAnne Borders
}

\begin{abstract}
Researchers only recently have begur to examine the enwironmental and contextual factors that infuence adolescent drinking behavior. The objective of this study was to create and lest a comprehensive model of adolsscent problem drinking. liems from the National Education Longitudinal Study: 1988-1994 (NELS:88; National Center for Educational Statistics, 1996) were used to create measurement modeis for all iatent wariables in the hypothesized sirucural model. Results indicated that high levels of parental support and a positive school climate in the sth grade influence the formation of relationships with peers with positive values in the ron grade that guarded against problem-dinking behavior in the toth grade.
\end{abstract}

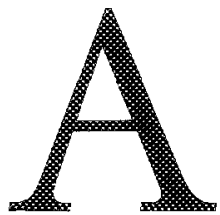

dolescents continue to use and abuse alcohol at alarming rates. In one recent survey, almost one third of high school seniors met the accepted criteria of problem or binge drinking, cefined as five or more consecutive drinks on at least one occasion in the previous 2-weeks (Bukstein, 1994). In another report, $27.9 \%$ of seniors, $21.1 \%$ of 10 th graders, and $13.4 \%$ of 8 th graders reported binge drinking behavior (Homonoff, Martin, Rimpas, \& Henderson, 1994). In addition, although ilicit drug use is declining, alcohol use among adolescents continues and is beginning at increasingly younger ages (Guthrie, Loveland-Cherry, Frey, \& Dielman, 1994). Peterson, Hawkins, Abbott, and Catalano (1994) found that $70 \%$ of adolescents reported they had used alcohol by the time they were 12 years old.

These trends are troubling, particularly given the demonstrated links between problem drinking and serious health, social, and behavioral problems in adolescents. Adolescent problem drinking behavior has a strong association with teenage pregnancy, delinquency, school misbehavior, aggressiveness, impulsiveness, and dropping out of school (Hawkins, Catalano, \& Miller, 1992). In addition, problematic use of alcohol during adolescence directly increases the risk of accidents, homicides, and sexually transmitted diseases, including AIDS (Peterson et al., 1994). Given the health and social risks involved in adolescent problem drinking, the prevention of youth substance abuse has become a national priority over the past two decades. Counselors in both school and community settings find themselves involved in primary and secondary prevention efforts when working with youth. As the gatekeepers of prevention, it is beneficial for counselors to be knowledgeable about past and current substance abuse prevention efforts.

Historically, prevention efforts have been rocused primarily cither on internal factors believed to influence youth substance use $(\mathrm{e}, \mathrm{g}$, self-concept and refusal skills $)$ or on a limited number of extemal antecedents (e.g, peer pressure) (Felner, Silverman, \& Adix, 1991). The emphasis on the socializing power of an adolescent's peers regarding deviant behavior has become particulary ingrained in the prevention literature. Peer influence theorists suggest that an adoiescent's selection of peers has a strong impact on the teen's likelihood to engage in problem drinking (Aseltine, 1995 ). School-based prevention research has successfully examined peer infuence as it contributes to problem drinking. A growing awareness in the prevention field, however, is that researchers now need to examine the social and envirommental context in which peer relationships are formed (Dielman, 1994).

Association with drug-using peers is one of the strongest single predictors of substance use among youth and adolescents (Hawkins et al., 1992). Adolescent perceptions of peer norms regarding the use of alcohol have been found to account for $10 \%$ to $40 \%$ of the variance in adolescents' use and misuse of alcohol (Guthrie et al., 1994). Relationships with prosocial peers (i.e, peers who have positive social and psychological capabilities and responsibilities) may serve as protective agents against problem drinking (Furrelmann, 1990). Catalano, Kosterman, Hawkins, Newcomb, and Abbot (1996) examined the influence of prosocial peer relationships and found significant relationships between prosocial opportunities, prosocial involvement, prosocial

J. Kelly Coke is an assistant professor in the Deparment of Educational Psycholugy at the University of Nevada, Las Vegas. $\mathrm{L}$. DiAmme Barders is chair of the Deparment of Counseling and Elucational Development at the University of North Carolina at Greensboro. This reseamh was supported by a grant from the American Educational Research Association, which receives funds for its "ARRA Grants Program" from the U.S. Department of Edacation's National Center for Educational Statistics and the Office of Eductional Research and Improvement, and the National Science Foundarion under NSF Grant \#RED9452861 . Opinions reffect those of the authors and do not necessarily reflect thase of the granting agencies. Correspondence regarding this artide should be sent to J. Kelly Coker, Deparment of Educational Psychology, 4505 Maryland Pewhasay, Bux 453003, Uniwersity of Nevada Las Vegas, Las Vegas, NV 89154-3003 (e-mail: kcoker@ccmail.nevada.edu). 
bonding and an absence of antisocial behavior including substance use.

In addition to peer relationships, parental relationships have a demonstrated impact on adolescent drinking behav. ior. Researchers have found that parents act to influence their developing adolescents' socialization through modeling, nurturing, and controlling behaviors (Maccoby \& Martin, 1983). In an extensive review of literature, Maccoby and Martin reported that aspects of parental support and control, in particular, have been widely substantiated as measures central in child and adolescent socialization. Supportive behaviors have been classified as those that foster a sense of belonging through warmth, responsiveness, and open communication. Controlling behaviors are those that establish guidance and flexibility in the power hierarchy of the family. Parenting behaviors such as rule setting and negotiation, discipline, punishment, permissiveness, and authority contribute to the level of control in a family (Maccoby \& Martin, 1983). Since Maccoby and Martin's review, these concepts of parental stipport and control have been examined in the substance abuse prevention literature. Foxcroft and Lowe (1995) examined the effects of parental support and control on adolescent substance use by using Maccoby and Martin's fourfold classification of parenting patterns that reflect the interaction between two major dimensions of perent-child behavior: support and control. Results of their questionnaire-based study indicated that adolescents who perceived indu!gent, authoritarian, or neglecting families were significantly more likely than those who perceived warmdirective families to say that they usually like to drink enough to get drunk (Foxcroft \& Lowe, 1995). To examine a truly contextual model of adolescent drinking behavior, it is necessary to examine other environmental variables significant to adolescents. In addition to family and peer factors, other environmental factors ( $e . g$, school and community climate) are beginning to show promise as potential contextual variables ir models of substance use behavior.

Given that most alcohol and drug prevention programs have been and continue to be school-based (Dielman, 1994; Lloyd, 1996), one might assume that there has been much research conducted on the effects of the school environment on adolescent substance abuse. In fact, adolescent perceptions of school environment or climate have only recently been identified as a factor deserving attention in understanding adolescent drinking and drug using behaviors. Weishew and Peng (1993) hypothesized that school variables, particularly school climate, were related to adolescent oroblem behaviors. The at thons defined positive school dimate as consisting of teacheradministrator cooperation, positive teacher attitudes toward students, sense of community, teacher praise, and attitudes emphasizing the expectation of academic success (Weishew \& Peng, 1993\}. Findings demonstrated that schools with better clinates, more positive student perceptions, and fair discipline were associated with lower rates of misbehavior among eighth graders Weishew \& Peng, 1993). The Social Ecology Model of adolescent substance use proposed by Kumpfer and Turner (1991) included measures of school climate.
Kumpfer and Turner suggested that youths who bond to prosocial irastitutions (i.e., schools) are less vulnerable to the effects of regative peers and subsequent substance use. This bonding to school is dependent on perceptions of positive schoo climates (i.e., schools with fair and clear rules, opportunities for rewards, and respect for students]. Both the school climate variable and the family climate variable in the Social Ecology Model successfully predicted school bonding and subsequent peer relationships and adolescent substance use.

Another factor gaining attention in the development of effective prevention programs is community involyement. The African proverb, "It takes a village to raise a child," stresses values of interdependence, extended family and community, and the primacy of children (Bomonoff et al, 1994). The positive impact of adolescent involvement in prosocial activities has been addressed in recent research. According to O'Brien and Rollefson [1995), opportunit:es for and participation in extracurricular activities both in the school and in the community foster a sense of community, the development of values of teanwork, individual and group responsibility, and enjoyment of leisure time. O'Brien and Rollefson found participation in activities and school success to be strongly associated. Because prevention research has often found strong school attachment to be a protective factor against adolescent substance abuse (Hawkins et al., 1992), the resuits of O'Brien and Rollefson's examination lend support to the need to include involvement in prosocial activities as a potential protective factor against adolescent problem ćrinking.

The examination of the impact of environmental variables on adolescent problem drinking increasingly occurs within a broader contextual framework. Resnick et al. (1997) used data collected from the National Longitucinal Study of Adolescent Health to idencify risk and protective factors at the family, school, and individual levels as related to four domains of adolescent health. Results indicated that parent-fanily connectedness and perceived school connectedness were protective against risky behaviors, including substance use. These authors concluded that adolescent risky behavior is affected by several envirommental contexts including farily and schools (Resnick et al., 1997).

The Social Ecology Model, a contextual and integrated model of aclolescent substance use, formed the basis for the current study (Kumpfer \& Tumer, 1991). The Social Ecology Model is grounded in social learning theory (Bandura, 1977) and control theory (Hirschi, 1969). The hypothesized model, therefore, emphasizes the importance of bonding to positively influencing varables such as family, school, and peers as a protection against the development of problem: behaviors such as alcohol abuse (Hawkins et al., 1992).

Given the need in prevention research to include a mezsure of community climate, a specific measure of drinking behavior, longitudinal research, and a large, representative database, the current model was developed (Dielman, 1994; Kumpfer \& Turner, 1991; Younge, Oetting, \& Deffenbacher, 1996). For the purposes of this study, we hypothesized that parental support, parental control, communify involvement, and positive school climates of students in the 8 th grade 
are positively related to the formation of relationships with peers with positive values in the 10 th grade, which is, in turn, negatively related to adolescent problem drinking in the 10th grade (see Figure 1).

We addressed four shortcomings of previous models of adolescent substance use. First, we included a community climate variable to examine the effect of an adolescent's involvement in community activities on drinking behavior. Kumpfer and Turner (1991) themselves suggested that data on the local neighborhood and community involvement would support the interactive nature of the Social Ecology Model. Second, we examined a specific measure of drinking behavior (i.e., binge drinking) as our outcome variable. In the past, prevention researchers have lised unrealistic outcome measures such as "lifetime use of alcoho" to represent problem behavior among adolescents (Dielman, 1994). Alcohol consumption in particular needs to be differentiated in research by frequency and duration of use because adolescent drinking behavior varies widely (Foxcroft, 1996). Binge-drinking behavior has been used in research as an outcome measure to characterize acolescent problem drinking (Arria, Tarter, \& Van Thie, 1991; Bukstein, 1994; Fomonoff et al., 1994). The number of drinks used to characterize binge-cirinking behavior for adolescents had traditionaly been set at five or more (Berkowitz \& Perkins, 1987; Nezleck, Pilkington, \& Bilbro, 1994). Results from studies wasing this definition have provided clear evidence of the link between binge drinking and serious social and behavioral problems (U.S. Department of Health and Human Services, 1993). Third, we examined the effects of environmental factors longitudinally instead of cross-sectionally at both the 8 th grade and 10th grade levels. According to Younge et al., (1996), longitudinal research is needed in studies of drug use among adolescents to identify and clarify patterns in relationships and possible causal infuences on drug using behavior. Fourth, we used a large, representative sample for data collection and analysis. We developed an expanded structural model based on the Social Ecology Model by Kumpfer and Tumer to examine longitudinal data from the Nationa Ecucation Longitudinal Study: 1988-1994 (NELS:88; National Center for Education Statistics [NCES], 1996) to better examine the causality of potential relationships.

\section{뜨ำ}

\section{NELS:88}

The third large-scale longitudinal study sponsored by NCES (1996), NELS:88, was designed to "provide trend date about critical transitions experienced by young people as they develop, attend school, and embark on their careers" (Owings, 1997, p. 95). Most of the 24,599 eighth-grade cohort was surveyed again in 1990, 1992, and 1994.

Sampling procedures. To provide comprehensive information on a nationally represented cohort of eighth grade studients in 1988 , the NCES used a two-stage stratified probability design to select the sample. A total of $\vdots, 052$ schools were selected through stratfied sampling and oversamping of private schools. Through random sampling of eighth-grade students in the participating schools, 24,599 eighth-grade students were selected as participants in the study in 1988. The NCES oversampled for Asian and Hispanic students to gather data on an ethrically diverse population of students. On average, 23 students represented each school. Surveys were completed by sudents as well as 1 parent, 2 teachers, and 1 school administrator per each participating student (U.S. Department of Education, 1996).

For the first-year follow-up survey in 1990, students were selected in two stages. In the first stage, 21,474 students who were in the original 8 th-grade sample were selected. Of the original cohort, 18,270 of these students were still cnrolled in school at the time of the first-year follow-up survey. In addition, 1,043 tenth graders who did not participate in the baseyear survey were rancomly selected from participating schools and added to the sample through a freshening process. Because some 10 th graders were not in the country or not in the 8 th grade during the data gathering in 1988 , the original sample

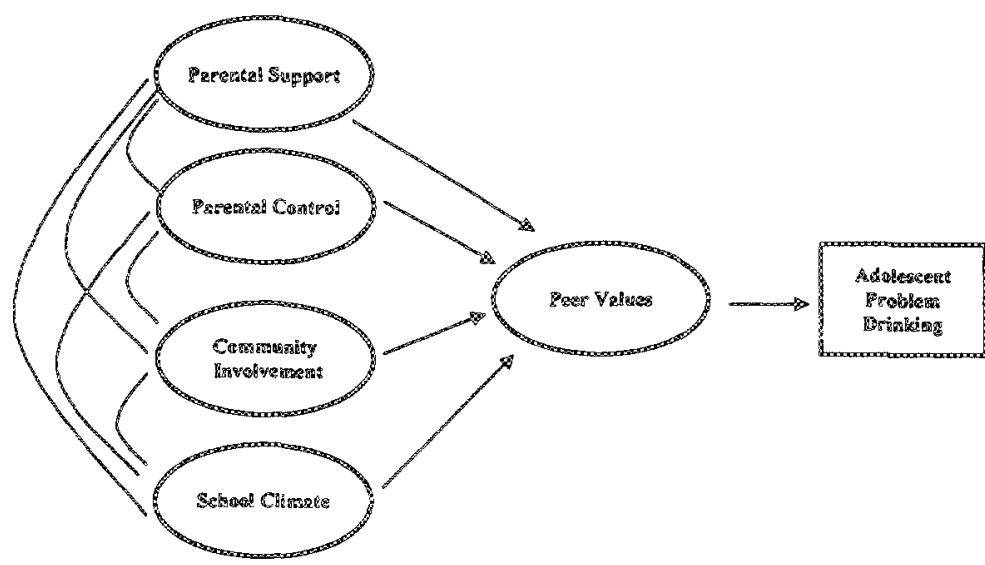

FGURE:

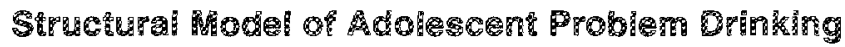


was augmented by a freshened sample of 1,043 tenth graders so that the resulting sample represented the 1990 national population of 10th graders U.S. Deparment of Education, 1996 .

Simey items. The selection of items in NELS:88 (NCES, $1996)$ for the base-year and first-year follow-up surveys was based on research issues outlined by the NCES. These issues included (a) students' academic growth over time, (b) the transition from eighth grade to high school, (c) the academic performance and school experiences of students with different cultural and ethnic backgrounds, (d) the process of dropping out of school, and (e) the features of effective schools (Owings, 1997).

Selected itens were broken down into key content areas to address the research issues. Examples of content areas inciude student perceptions of equity, access, and choice within the school and home environments; parental involvement; and transition patterns in the student's life (S. S. Pengi personal communication, June 19, 1997). The student questionnaire in the base-year survey provided data on students' backgrounds, extracurricular activities, school work, educational and occupational aspirations, and social and familial relationships. The first-year follow-up survey gathered information on students' school and home environment, course work, extracumicular activities, employment and education aspiraticns, and self-concept (U.S. Department of Education, 1996).

\section{Parricipants}

Given the longitudinal nature of this analysis, the sample comprised respondents who participated in both the 1988 base-year survey and the first-year follow-up survey in 1990. Those students who met this criterion $(N=17,424)$ were identified in the data set by using the first-year follow-tap flagging variable for base-year and first-year participants. This variable indicates the completion or noncompletion of a questionnaire in both 8 th and 10th grade U.S. Department of Education, 1996). The use of the flagging variable also eliminated any participants from both the base-year and first-year follow-up survey who did not respond to any items on the survey. The first-year follow-up panel weight variable was also selected for this analysis. This design weight, available in NELS:88 (NCES, 1996), allows for longitudinal examination of the 1988 cohort 2 years later in 1990. The design weight is also used in analysis to reflect the national or regional population estimate that is derived from the sample and to adjust for differential selection probabilities of Asian students, Hispanic students, and private school students (U.S. Department of Education, 1996).

\section{Procedure}

The NCES (1996) has provided an electronic codebook along with a compact disc containing all data from the NELS:88 base-year, first-year follow-up, and second-year follow-up survey. The electronic codebook was used to "tag" potential items for this analysis. Survey items suspected to represent the observed factor of problem drinking and the latent factors of parental support, parental control, and school cimate were selected based on their use in past research using the NELS:88 dataset (Dewalt, 1993; Trusty \& Lampe, 1997; Weishew \& Peng, 1993) and on the current review of literature. We selected items suspected to represent conmunity involvement and relationships with peers with positive values basec on the hypothesized significance of these items in the current research.

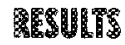

\section{Goodness of Fit}

The goodness of ft for each measurement model was examined using AMOS 3.6 (Arbuckle, 1996). Three of the more widely used and commonly accepted fit indicators (Schumacker \& Lomax, 1996), the chi-square $\left(\chi^{2}\right)$, goodness-of-fit index (GF) and the root mean square error of approximation (RMSEA), were used as fit indices for each measurement model (see Table I).

Although commonly used in structural equation modeling, the chi-square may be an unreliable measure of fit for larger sample sizes (Schumaker \& Lomax, 1996). Given the unreliability of this indicator, the GFI and RMSEA were also reported for each measurement model and the full model. The closer the GFI is to 1 , the better the implied fit of the hypothesized model (Arbuckle, 1996). A general rule of thumb in determining model fit based on the RMSEA is that a value equal to or less than 05 indicates a close fit of the model in relation to the degrees of freedom (Schumacker \& Lomax, 1996).

\section{Exagenows Variables}

Measurement models created for each exogenous latent variable in the hypothesized model were tested through factor analysis using SPSS 7.5 (1998). Because the items selected for the current analysis were primarily grounded in past research and theory, the confirmatory factor analysis procedure was used (Schumacker \& Lomax, 1996). As a rule of thum:b, those items from NELS:88 (NCES, 1996) with significant factor loadings of 30 or higher were used to make up each measurement model. However, in the instance of the latent variable, Parental Support, one item with a factor loading lower than 30 (parents attended a school meeting) was accepted due to consistent support in the literature for its inclusion. In their 1997 investigation using NELS:88, Trusty and Lampe found that students' perceptions of parental involvement in school-based activities was a significant indicator of parental support.

GFI indices for all hypothesized exogenous measurement models ranged from 990 to 994 , suggesting a strong fit for all exogenous variables in the full model. The RMSEA indices ranged from 012 to .054 for all hypothesized exogenous measurement, suggesting strong fit of the selected NELS:88 (NCES, 1996) items to the latent variables. All of the factor loadings for the NELS:88 items in the exogenous measurement models indicated rea- 


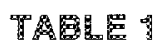

F径

\begin{tabular}{|c|c|c|c|c|}
\hline \multirow[b]{2}{*}{ PELS:83 } & \multicolumn{4}{|c|}{ Exogenous Yarlables } \\
\hline & Paremial support & Parentel Control & $\begin{array}{l}\text { Community } \\
\text { 8nvobvement }\end{array}$ & School Climate \\
\hline $\begin{array}{l}\text { Discuss programs as } \\
\text { school with parents } \\
\text { (Support 1) }\end{array}$ & .56 & & & \\
\hline $\begin{array}{l}\text { Discuss school activities } \\
\text { with parents (Support } 2 \text { ) }\end{array}$ & .66 & & & \\
\hline $\begin{array}{l}\text { Discuss things studied in } \\
\text { class with parents } \\
\text { (Support } 3 \text { ) }\end{array}$ & .51 & & & \\
\hline $\begin{array}{l}\text { Parents attended a school } \\
\text { meeting (Support 4) }\end{array}$ & .23 & & & \\
\hline $\begin{array}{l}\text { Parents attended a school } \\
\text { event (Support } 5 \text { ) } \\
\text { How often parents check }\end{array}$ & .35 & & & \\
\hline $\begin{array}{l}\text { How often parents chack } \\
\text { on homework (Control i) }\end{array}$ & & .41 & & \\
\hline $\begin{array}{l}\text { How often parents } \\
\text { requirs chores done } \\
\text { Control }\end{array}$ & & 38 & & \\
\hline $\begin{array}{l}\text { How often parents limit } \\
\text { watching TV (Control } 3 \text { ) }\end{array}$ & & .56 & & \\
\hline $\begin{array}{l}\text { How often parents limit } \\
\text { going out with friends } \\
\text { (Control 4) }\end{array}$ & & .48 & & \\
\hline $\begin{array}{l}\text { Participated in religious } \\
\text { youth groups (Comm i) }\end{array}$ & & & .63 & \\
\hline $\begin{array}{l}\text { Participated in } \\
\text { neighborhood clubs } \\
\text { (Comm 2) }\end{array}$ & & & .83 & \\
\hline $\begin{array}{l}\text { Participatsd in non- } \\
\text { school feam sports } \\
\text { (Comm 3) }\end{array}$ & & & .82 & \\
\hline $\begin{array}{l}\text { Perticipeted in Y or other } \\
\text { youth groups (Comm } 4 \text { ) }\end{array}$ & & & .82 & \\
\hline $\begin{array}{l}\text { Participated in summer } \\
\text { programs (Comm } 5 \text { ) }\end{array}$ & & & .78 & \\
\hline $\begin{array}{l}\text { Students get along well } \\
\text { whth reachers (School i) }\end{array}$ & & & & .52 \\
\hline $\begin{array}{l}\text { There is real school spirit } \\
\text { (School 2) }\end{array}$ & & & & .40 \\
\hline $\begin{array}{c}\text { The teaching is good at } \\
\text { school (School 3) }\end{array}$ & & & & .73 \\
\hline $\begin{array}{l}\text { Teachers are interested } \\
\text { in students (School 4) }\end{array}$ & & & & .79 \\
\hline $\begin{array}{l}\text { Teachers praise my } \\
\text { efforts (School } 5 \text { ) }\end{array}$ & & & & .57 \\
\hline $\begin{array}{l}\text { Chi Square }\left(x^{2}\right) \\
\text { GF } \\
\text { RMSEA }\end{array}$ & $\begin{array}{c}275.40(d f=5, \rho=.001) \\
.994 \\
.054\end{array}$ & $\begin{array}{c}6.91(d f=2, p=.05) \\
.990 \\
.012\end{array}$ & $\begin{array}{c}37.07(d f=5, p=.001) \\
.990 \\
.026\end{array}$ & $\begin{array}{c}683.08(d f=5, p=.001) \\
.990 \\
.046\end{array}$ \\
\hline
\end{tabular}

Note. NELS:88 = National Education Longitudinal Study: 1988-1994; Support = Parenta: Support; Control = Farantal Controi; Comm = Comunnity Involvement; School = School Climate; $Y=Y$ MCA or YWCA; GFI = goodness-of-fit index; RoMSEA = root mean square error of approximaion. All factor loadings were signiflcant at of level $(\rho<.01)$.

sonable fir (ranging from 23 to .83 ) for the hypothesized models and were significant at the .01 level (see Table 1 ).

\section{Endogenoris Toriables}

Peer values. It was hypothesized in the model that the var:able, Peer Values, is directly influenced by the exogenous variables in the model and that this variable then influences adolescent problem drinking. For the present analysis, items from the first-year follow-up of NELS:88 (NCES, 1996) that reflected involvement with peers with positive values were selected to specify the latent variable Peer Values. All items hypothesized to represent Peer Values were reverse-scored to better reflect the full hypothesized model. Responses for all items ranged from 1 (very important) to 3 (not important). As with the exogenous variables, the chi-square for Peer Val- 
ues was significant $\left(x^{2}=76.49, d f=4, p<.001\right)$. The GFI for the latent variable Peer Values was .990 and the RMSEA was .032 , suggesting a strong fit for the model. Five of the items selected from NELS:88 to make up the measurement model Peer Values exhibited factor loadings ranging from 29 to .79 , and were significant at the 01 level (see Table 2). Although one item in the measurement model had a factor loading of less than 30 (among friends, how important to play sports"), the decision was made to setain the item given its close proximity to the cut-off value of 30 , and the support for its inclusion in the literature (Catalano et al., 996; Kumpfer \& Tumer, 1991).

Adolescent problem drinking The final outcome variable, Adolescent Problem Drinking, was an observable variable in the full hypothesized model. Given the widespread use in prevention research of binge drinking as a measure of problem drinking Bukstein, 1994; Dewait, 1993; Foxcrof \& Lowe, 1991; Homonofl et al., 1994), the question in NELS:88 (NCES, 1996) that directly surveys singe drinking behavior was used in this analysis. The question in the first-year follow-up survey of NELS: 88 used to define Adolescent Problem Drinking is "Think back over the last 2 weeks. How many times have you had five or more drinks in a row?" (NCES, 1996).

The cumulative percentage of respondents from the full sample $(N=17,424)$ who reported engaging in binge drinking behavior at least one time in the previous 2 weeks at the time of the survey was $21 \%$. This frequency of binge drinking among 10 th graders in 1990 substantiates other research that has suggested that binge drinking occurs among approximately one third of adolescents (Bukstein, 1994; Homonoff et al, 1994). Given that the ultimate endogenous variable is an observable variable specified by one item in the NELS:88 (NCES, $1996)$ data set, the regression weight $(-.45)$ found using AMOS 3.6 (Arbuckle, 1996) represents the direct relationship between Peer Values and Adolescent Problem Drinking.

\section{Full Mpotheszized Mode?}

Given that the variable Peer Values was hypothesized to mediate relationships between the exogenous variables and the outcome variable in the full model, it was tested for sig-

\section{TALE 2}

\section{Factor hodings of litems in NHLS:88 for Peer Values}

\begin{tabular}{|c|c|}
\hline MEES: & Paer Values \\
\hline $\begin{array}{l}\text { Among friends, how important to play } \\
\text { sports (Peers 1) }\end{array}$ & .29 \\
\hline $\begin{array}{l}\text { Among friends, how important to get } \\
\text { good grades (Peers 2) }\end{array}$ & .79 \\
\hline $\begin{array}{l}\text { Among fiends, how important to } \\
\text { continue education (Peers 3) }\end{array}$ & .78 \\
\hline $\begin{array}{l}\text { Among friends, how important to have } \\
\text { a job (Peers } 6 \text { ) }\end{array}$ & .30 \\
\hline $\begin{array}{l}\text { Among friends, how important to be } \\
\text { popular with studerts (Peers ?) }\end{array}$ & .35 \\
\hline
\end{tabular}

Note. See Table 1 Note. Peers $=$ Peer Values. All factor loadings were significant at .01 level $\{\rho<.01\}$. nificance as a medisting variable as a first step in this data analysis. According to Baron and Kenny (1986), a variable functions as a mediator "to the extent that it accounts for the relation between the predictor and the criterion" (p.1176). When variations in the presumed mediator significantly account for variations in the dependent variable over and above the direct relationship between the predictor(s) and the dependent variable, the given mediator is significant (Baron \& Kenny, 1986 ).

In AMOS 3.6 (Arbuckle, 1996), all potential direct and indirect paths to Adolescent Problem Drinking were examined to test the significance of the mediating variable, Peer Values. In this analysis, we compared direct paths from the exogenous variables (i.e., Parental Support, Parental Control, Community Involvement, and School Cimate) to the outcome variable, Adolescent Problem Drinking, with the indirect paths as mediated by Peer Values. According to Baron and Kenny (1986), having path coefficients from the exogenous variables to the outcome variable that are not statisticaly significant, or that are significantly less than the mediating variable's path coefficients, demonstrates that the given mediator is indeed potent.

Figure 2 shows all possible path ceefficients to the final outcome variable, Adolescent Problem Drinking. All paths from the exogenous variables to the mediating variable were significant at the .01 level $(p<.01)$. By comparison, two of the direct path coefficients to Adolescent Problem Drinking were not significant (i.e., Parental Control, School Climate), and the other lirect paths (i.c., Parental Support, Community involvement) were significant at the 05 level $(p<.05)$, but showed no real direct effects on the outcome variable (see Figure 2). These findings suppotted the existence of the mediating variable, Peer Values, for the full hypothesized model.

\section{Testing the Ful Hypothesized Model}

The full hypothesized model was examined in AMOS 3.6 (Arbuckle, 1996) for strength and significance of standardized regression weights, comrelations among the factors, and goodness-of-fit indices (see Figure 3).

Goodness of fit. Because of the large sample size, the chisquare of the full model was significant $\left(x^{2}=5869.34, d f=\right.$ $264, p<.001$ ). The GFI for the full model was .97, and the RMSEA was .035, both indicating strong fit for the full model.

The direct path between Peer Values and Adolescent Problem Drinking $(-.451)$ was negative and significant, suggesting that relationships with peers with positive values did guard against problem drinking behavior anong adolescents in 10 th grade.

Both Parental Support (.248) and School Climate (.111) had positive, significant relationships on the mediating variable, Peer Values. This suggests that high levels of parental support and a positive school climate in 8 th grade infuenced the formation of relationships with peers with positive values in 10 th grade. The effects of both Parental Control and Community Inyolvement on Adolescent Problem Drinking as mediated by Peer Values were significant but very low $(046,-.051$, respectively). This finding suggests that high evels of parental control and involvement in the 


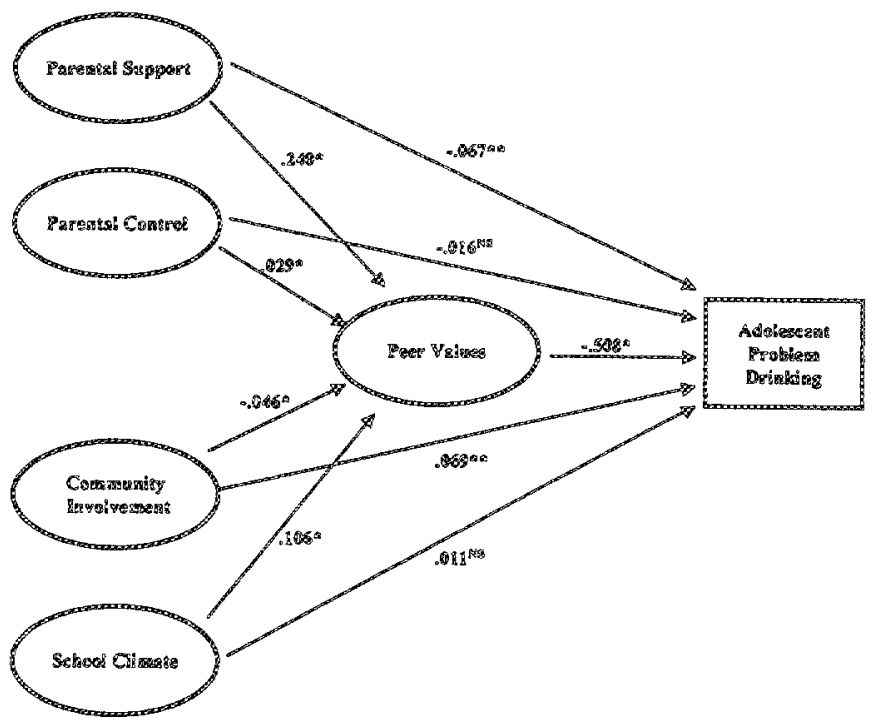

Plorera

\section{Standardized Factor loabings and Signitheance of Mediating Variabie, Por Vallas}

Note. NS = not statistically signiticant.

$" p<.01 .{ }^{* *} p<.05$.

community in 8 th grade did not strongly influence the formation of relationships with peers with positive values in loth grade.

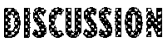

The purpose of this study was to create and test a contextual model of the factors that influence adolescent problem drinking. For the full model, results indicated that Peer
Values did serve as a mediatirg factor for all exogenous variables in the full model. The exogenous variables, Parental Support and School Cimate, significantly infuenced the formation of relationships with peers with positive values in 10 th grade, which had a strong negative relationship with Adolescent Problem Drinking in 10 th grade. The other exogenous variables, Parental Control and Community Involvement, showed little influence on adolescent problem drinking as mediated by peer values for the hypothesized model. Parental Support seemed to have a stronger influence on the formation of relationships with peers with positive values than did School Climate.

The full structural model of contextual factors that inficence adolescent problem drinking stibstantiates the use of both longitudinal analysis and an examination of adolescent problem drinking as a specific outcome variable. School and community counselors working with young adolescents can infer from the fincings that eightin graders who experience relationships with parents and school personnel who express interest, praise, and an ability to listen are more likely to be involved with peers who value ecucation and positive social interactions 2 years later. Counselors and other positively influencing adults who then work to foster relationships between adolescents and peers with positive values will help guard against binge drinking behavior in the 10th grade.

Two hypothesized relationships were not substantiated in the current study. First, high levels of parental control did not indirectly influence adolescent problem-drinking behavior as nediated by relationships with peers with positive values. Second, high levels of community involvement did not indirectly influence adolescent problem-drinking behavior as mediated by the peer variable.

The lack of an indirect relationship between Parental Control and Adolescent Problem Drinking as mediated by

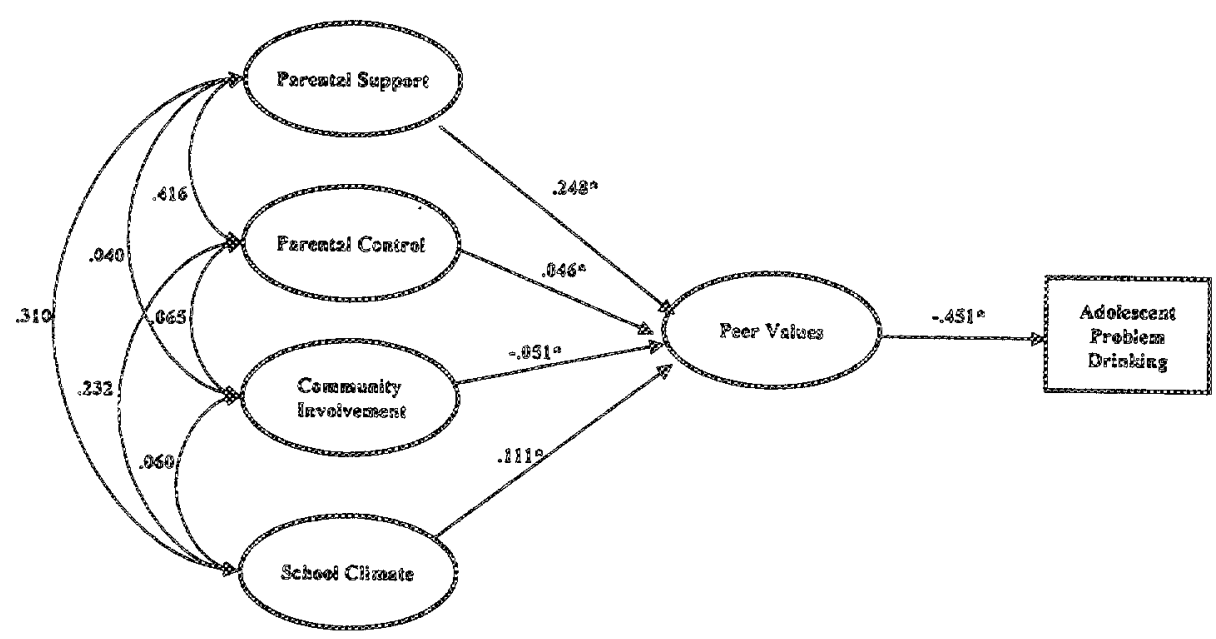

POURE

Full Mods a Fators

$* 0<.01$ 
Peer Values might be accounted for by its separation in the hypothesized mocel from Parental Support. In the current analysis, we followed models set by previous researchers (Chilcoat \& Anthony, 1996; Lowe \& Sibley, 1991) and separated these two factors to better understand the specific types of parent-adolescent interaction that accounted for selection of peers and subseguent drinking behavior. The higher correlation between the latent variables Parental Support and Parental Control in the current analysis (.416), however, points to the need to examine the relationship between these two variables and their combined effects on adolescent problem drinking. Researchers who have examined parent-adolescent relationships have often found that it is the interaction between Parental Support and Parental Control that serves to foster positive behaviors and to guard against negative behaviors (Foxcroft \& Lowe, 1995; Maccoby \& Martin, 1983). Future models of the factors that influence adolescent problem drinking might benefit from examining the interactive effects of Parental Support and $\mathrm{Pa}-$ rental Control on Acolescent Problem Drinking.

The lack of a significant relationship between high levels of community involvement in 8 th grade and relationships with peers with positive values in 10 th grade may be due to the cperational definition of the latent variable Community Involvement in the current analysis. The current analysis included only those items that represented an eighth graders' current involvement in community-based activities. Given the lack of avallability in the NELS:88 NCES, $1996)$ data set, the latent variable Community Involvement did not include items that assess other community factors suggested for study by prevention researchers (e.g., an adolescent's perceived opportunities for involvement in their community, a community's socioeconomic status, the value placed on such involvement by peers or family members; Catalano et al., 1996; Graham, i 996). A more comprehensive community variable including these factors would further our understanding of this potentially critical variable in the field of substance abuse prevention.

\section{Implications for Research}

Increasingly, substance abuse prevention fforts are targeting youths at younger and younger ages, although there has been little research to examine factors that guard against substance use before it happens (Flewelling \& Bauman, 1990; Younge et a1., 1996). Results of the current study substantiate Hurrelmann's (1990) findings that stable and dependable relationships with parents in the early phases of adolescence serve to foster positive personality development and decision making at the age of adolescence. In addition, the current study provides information regarding the protective value of a positive school climate in earlier years and how it affects the formation of positive peer relationships. The school context is one factor that until now has escaped longitudinal examination as an enduring protective factor for young adolescents. Including a specific measure of problem-drinking behavior is another factor that deserves continued attention in research.
As examination of different levels of binge-drinking behavior (i.e, "one-time use" versus "four-to-six-time use") may shed light on the social relationships that differentiate experimental versus chronic binge drinking. For example, do adolescents who engage in chronic binge-drnking behavior report lower parental support than do adolescents whose use is more experimental? Are chronic users more likely than experimental users to have relationships with antisocial peers? Finally, do chronic binge drinkers experience more negative school climates, or do they even go to school at all?

\section{Implications for Proctice}

School and community counselors alike often work with adolescents through the most crucial years of their development. To date, prevention and intervention programs targeted at younger adolescents have focused primarily on internal factors (i.e., self-concept) and the development of refusal skills (i.e., "just say no"). These past efforts have been based largely on assumptions about adolescent decision making ani behavior (Botvin \& Botvin, 1992). The current findings provide a foundation upon which counselors can work to buld effective prevention programs.

By examining the contextual framework in which the young adolescent ives, counselors can gain a better urderstanding of those factors that affect adolescents' decisions about friendships and drug use, and how to use those factors in prevention efforts. In addition, effective prevention programs based on the current findings could provide training and information to positively influencing aduls (i.e., parents, teachers, counselors) on the importance of the contextual environment in which the adolescent lives. Specifically, counselors could help parents and teachers learn how to enhance their roles as mentors, communicators, and support systems for young adolescents. These positively influencing adults also could be encouraged to provide opportanities for involvement in activitics (i.e., community involvement, school involvement) in which positive peer relationships might form and flourish.

The importance of the peer relationship has been substantiated in the current study. In addition, the strong protective nature of relationships with peers with positive values has been identified. Counselors who include positively influencing peers in their prevention efforts as leaders, cofacilitators, and teachers will encourage relationships with positively influencing and protective peers. Peer mentoring and peer mediation programs already in place in schools could serve for counselors as excellent testing grounds in which to incorporat other prevention activities.

Finally, the current research provides the groundwork for a prosocial versus a deficit model of substance abuse prevention. Through individual and group counseing, counselors could work to identify positive and supporting relationships in an adolescent's life and encourage the formation of such relationships where they do not exist. Whether they realize it or not, counselors are engaged in prevention activities on a regular basis in their work with children and adolescents. By maintaining an awareness of their young clients' environ- 
mental and contextual world, counselors can intentionally work to foster the protective factors necessary to prevent adolescent problem drinking.

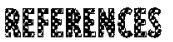

A.buckle, J. (1996). AMOS [Version 3.6) [Computer software]. Chicago: Snalwaters Corporation.

Arria, A. M., Tarter, R. E., \& Van Thiel, D. H. (1991). The effects of alcohol abuse on the health of adolescents. Alcohol Healh and Research World, 15, 52-57.

Aseltine, R. H. (1995). A reconsideration of parental and peer influences on adolescent deviance. Joumal of Healih and Social Behavion $36,103-121$.

Bandura, A. (1977). Social leaning theony. Englewood HIlls, NV: Prentice-Hall.

Baron, R. M., \& Kenny, D.A. (1986). The moderator-mediator variable distincfion in social psychological research: Conceptual, strategic, and statistical considerations. Joumal of Personality and Sorial Psychology, 51, 1173-1182.

Berkowitz, A. D., \& Perkins, H. W. (1987). Recent research on gender differences in collegiate alcohol use. American College Health, 36, 123-129.

Botvin, G. J., \& Botvin, E. M. (1992). Adolescent tobacco, akohol, and drug abuse: Prevention strategies, empirical findings, and assessment issues. Developmental and Behavioral Pediatrics, 13, 290-301.

Bukstein, O. G. (1994). Treatment of adolescent alcohol abuse and dependence. Alcohol Health and Research World, 18, 296-301.

Catalano, R. E., Kosterman, R., Hawkins, J. D., Newcomb, M. D. \& Abbott, R. D. (1996). Modeling the etiology of adolescent substance use: A test of the social development model. Joumal of Drug issues, 26, 429-455.

Chilcoat, H. D., \& Anthony, J. C. (1996). Impact of parent monitoring on initiation of drug use through late childhood. Joumal of American Academy of Child Adolescent Psychiamy, 35, 91-100.

Dewalt, M. W. (1993). Using youth group participation variables and smoding to predict drig wse in a national sample. Paper presented at the anmual meeting of the American Educational Research Association, Atlanta, GA. (ERIC Document Reproduction Service No. ED 363 558)

Dielman, T. E. (1994). School-based research on the prevention of adolescent alcohol use and misuse: Methodological issues and advances. Joumal of Researcin on Adolescents, 4, 271-293.

Felner, R. D., Silverman, M. M., \& Adix, R. (1991). Prevention of substance abuse and related disorders in childhood and adolescence: $A$ developmentally based, comprehensive ecological approach. Family Conmumity Health, 14, 12-22.

Flewelling, R. L. \& Bauman, K. E. (1990). Family structure as a predictor of initial sibstance use and sexual intercourse in early adolescence. Joumal of Marriage and the Family, 52, 171-181.

Foxcroft, D. R. (1996). Adolescent alcohol use and misuse in the UK. Edrucational and Child Psychology, 13,60-68.

Foxcroft, D. R. \& Lowe, G. (1991). Adolescent drinking behaviour and fantly socialization factors: A metaranalysis, Joumal of Adolescence, 14, 255-273.

Foxcroft, D. R., \& Lowe, G. (1995). Adolescent dritking, smoking, and other substance use involvement: Links with perceived family life. Joumal of Adolescence, 18, 159-177.

Graham, N. (1996). The influence of predictors on adolescent drug use: An examination of individual effects. Youth and Society, 28, 215-235.

Guthrie, B.J., Loveland-Cherry, C., Frey, M. A., \& Dielman, T. E. (1994). A theoretical approach to studying health behaviors in adolescents: An at-risk population. Family Community Health, 17, 35-48.

Hawkins, J. D. Catalono, R. . . \& Miller J. Y. (1992). Risk and protective factors for alcohol and other drug problems $n$ adolescence and early adulthood: Implications for substance abuse prevention. Psychological Bulletin, $112,64-105$
Hirschi, T. (1969). Causes of delinuanchy. Berkeley, CA: University of Colifornia Press.

Homonoff, E., Martin, J., Rimpas, D., \& Ienderson, M. (1994). It takes a village to rise a child: $A$ model of training for prevention of youth abuse of alcohol and other drugs. Child and Adolescent Social Work Joumcl, 11, 53-61.

Hurrelmann, K. (1990). Parents, peers, teachers, and other significant partners in adolescence. International Jourmal of Adolescence and Youth, 2, 21]-236

Kumpfer, K. I., \& Turrer, C. W. (1991). The social ecology model of adolescent substance abuss: Implications for prevention. The International Joumal of the Addictions, 25, 435-463.

Lloyd, 3. [1996). Alcohol and young people: A case for supporting education about alcohol in primary and secondary schools. Educational Reniew, 48, 153-161.

Lowe, G., \& Sibley, D. (1991). Boundary enforcement in the home environment and adolescent alcohol use. Family Dynamics Addiction: Quarterly, $1,52-58$.

Maccoby, E., \& Martin, J. (1983). Socializing in the context of the family: Parent-child interaction. In P. H. Mussen (Ed.), Handbook of child psychology (pp. I-102). New York: Wiley.

National Center for Education Statistics [Producer and Distributer]. (1996). National Education Longitudinal Study: 1988-1994 [Data files and electronic codebook system!. Washington, DC: Author.

Nezleck, J. B., Pilkington, C. J., \& Bilbro, K. G. (1994). Moderation in excess: Binge drinking and social interaction among college students Jourmal of Studies on Alcohol, 55, 342-351.

O'Brien, E. \& Rollefson, M. (1995). Extracurricular participation and siudent engagement. Eatucation policy issues: Siatistical perspectives (Report No. NCES 95-741]. Washington, DC: Policy Studies Associates. (ERIC Document Reproduction Service No. ED 384 097)

Owings, J. (1997, June). NEISS:88: National education longitudinal study of 1988. In S. S. Peng (chair), NCES National Longitudinal Databose Training. Training corducted at \$ynetics, Inc, Rockvile, MD.

Peterson, P. L., Hawkins, J. D., Abbott, R. D. \& Catalano, R. F. (1994) Disentangling the effects of parental drinking, family management, and parental alcohol norms on current drinking by Black and White adolescents. Joumal of Research on Adolescents, 4, 203-227.

Resnick, M. D., Bearman, P. S., Blum, R. W., Bauman, K. E., Harris, K M., Jones, J., Tabor, J., Beuhring, T., Sieving, R. E., Shew, M., Ireland, M. Bearinger, L. H., \& Udry, I. R. (1997). Protecting adolescents from harm: Findings from the National Longitudinal Study on Adolescent Health. Joumal of the American Medical Association, 278, 823-832.

Shumacker, R. F., \& Iomax, R. G. (1996). A beginners guide to structural equation modeling. Mahwah, NJ: Eribaum.

SPSS 7.5 [Conputer software]. (1998). Chicago: SPSS lnc.

Trusty, J., \& Lampe, R. E. (1997). Relationship of high-school seniors' perceptions of parental involvement and control to seniors locus of control. Joumal of Counseling \& Development, 75, 375-384.

U.S. Department of Education, Office of Educational Research and Improvement. (1996). National education longindinal study of 1988 (NELS:88). Research framework and isszes (Working Paper No. 9603). Washington, DC: Author.

U.S. Department of Health and Human Services, Center for Substance Abuse Pruvention. (1993). Prevention primer: An encyclopedia of alco. hol, tobacoo, and other dug prevention terms. Rockville, MD: National Clearnghouse for Alcohol and Drug lnformation.

Weishew, N. L., \& Feng, S. (1993). Variables predicting students" problem behaviors. Joumal of Educational Research, 87, 5-17.

Younge, S. L., Oetting, E. R., \& Deffenbacher, J. L. (1996). Correlations among maternal rejection, dropping out of school, and drug use ir adolescents: A pilot study. Joumal of Climical Psychology, 52, $96-102$ 